\title{
Revisiting the Physician's Approach to Lesbian and Bisexual Patients in Lebanon
}

\section{Zeinab Kassem, MD ${ }^{1}$ Hasan M Abdessamad, MD $^{2}$}

To cite this article: Kassem, Z. and Abdessamad H. (2019). Revisiting the Physician's Approach to Lesbian and Bisexual Patients in Lebanon. Al-Raida, 43(1), 49-58

(C) 2019 The Author(s)

Corresponding author: Hassan M Abdessamad, MD

Author contact: hasanabdessamad@chifranciscan.org

Article type: Research article

Article accepted: $10^{\text {th }}$ August 2019

Published online: 30 ${ }^{\text {th }}$ September 2019

Publisher: Arab Institute for Women

Publication support provided by: Escienta

Journal ISSN: 0259-9953

Copyright: This is an Open Access article, free of all copyright, and may be freely reproduced, distributed, transmitted, modified, built upon, or otherwise used by anyone for any lawful purpose. The work is made available under the Creative Commons Attribution (CC-BY) 4.0 license. 


\title{
Revisiting the Physician's Approach to Lesbian and Bisexual Patients in Lebanon
}

\author{
Zeinab Kassem, $M D^{1}$, Hasan M Abdessamad, $\mathrm{MD}^{2}$ \\ ${ }^{1}$ Eastern Virginia Medical School, Norfolk, VA, USA \\ 2 Highline Medical Center, Department Chair of Obstetrics \& Gynecology, Burien, WA, USA
}

\begin{abstract}
Health disparities among sexual minority groups exist worldwide. Lesbian and bisexual women face barriers to healthcare access and provision. Disparities are even more striking in Middle Eastern countries like Lebanon. This paper assesses healthcare resources and practices pertaining to sexual minority women in Lebanon. We found a significant scarcity of research on lesbian or bisexual women coming out of Lebanon or the Middle East. We call for enriching the literature with such research to better understand the needs of women and recommend effective interventions.
\end{abstract}

Keywords: Access to care, barriers to care, bisexuality, lesbian, sexual orientation, WSW

Introduction

The lesbian, gay, bisexual and transgender (LGBT) community experiences unique health disparities worldwide (Pan American Health Organization, 2013). Yet, health issues vary widely among different subgroups of this population (Institute of Medicine [IOM], 2011). Both in the United States and in Lebanon, there exists a lack of training and preparation for physicians to provide adequate healthcare to different members of the LGBT community (Dean et al., 2000; ElKak, 2009). While some efforts have been made in the U.S. to improve this issue, attempts in 
Lebanon have been marginal. Research done on LGBT health is relatively scarce (Blosnich et al., 2014). A report published in 2011 by the Institute of Medicine confirms this knowledge gap:

To advance understanding of the health needs of all LGBT individuals, researchers need more data about the demographics of these populations, improved methods for collecting and analyzing data, and an increased participation of sexual and gender minorities in research. (IOM, 2011)

While this applies to all members of the LGBT community, the primary focus of this paper will be addressing the healthcare issues of lesbian and bisexual women, and women who have sex with women (WSW). For the rest of this paper, these groups will be collectively referred to as sexual minority women (SMW). It is necessary to look closer at the medical practices of healthcare professionals caring for this underrepresented population to help identify shortcomings, and strategize how to overcome them.

\section{Sexual Minority Women's Health Risks}

As is the case with sexual minority men, SMW have a higher prevalence of certain psychological and medical conditions when compared to heterosexual women. Studies conducted in the U.S. show that lesbian and bisexual women are more likely than their heterosexual counterparts to engage in maladaptive behavior (American College of Obstetricians and Gynecologists, 2005; Pan American Health Organization, 2013). Smoking and alcohol consumption are higher in lesbian and bisexual women (American College of Obstetricians and Gynecologists, 2005; Substance Abuse and Mental Health Services Administration, 2012; Blosnich et al., 2014). Multiple studies have shown an increased rate of the following morbidities in SMW as compared to heterosexual women: heart disease, obesity, breast cancer, depression, post-traumatic stress disorder, and suicidal attempts (American College of Obstetricians and Gynecologists, 2005; Substance Abuse and Mental Health Services Administration, 2012). Contrary to common misconceptions, SMW are at risk of acquiring sexually transmissible infections (STIs) (Diamant et al., 2000) despite this being perceived as low-risk by physicians and patients alike (American College of Obstetricians and Gynecologists, 2005; Ripley, 2011). Factors that increase their risk of acquiring STIs include having sex with men (Lee, 2004), and sharing sex toys (Ripley, 2011). Studies have shown that bacterial vaginosis has been identified in 24 to $52 \%$ of women who have sex with women (Marrazzo, 2000; Marrazzo et al., 2002). 
Further, a study conducted in the U.S. in 2010 found that lesbians are 30\% less likely than heterosexuals to get a routine physical examination within the span of a year (Blosnich et al., 2014). Physician failure to conduct patient interviews in a "sensitive and nonjudgmental manner" is considered a contributing factor (Pan American Health Organization, 2013). The American Cancer Society (2005) released a booklet stating that fear of discrimination and having negative experiences with healthcare providers are two of the major reasons why SMW avoid seeking proper healthcare. Certain skills can be adopted by healthcare providers to improve patient access to care. Factors that increase the likelihood of "coming out" to one's physician include: being asked about one's sexual orientation, filling out an intake form that allows writing down one's sexual orientation, and trusting the confidentiality of the information provided (Davis et al., 2000). In light of the true or perceived homophobia or heterosexism that SMW face within the healthcare system, certain institutions have been established to address such health disparities. For example, the Gay and Lesbian Medical Association (GLMA) in the U.S. published specific guidelines for physicians to adhere to, in order to be regarded as LGBT-friendly (2017). Specifically, they devised a range of interventions from merely displaying a rainbow flag in the physician's office to modifying question formats during patient interviews (GLMA, 2006). In addition, the Human Rights Campaign (HRC) publishes annual Health Equality Indices that rank hospitals based on their commitment to LGBT equality and inclusion (2017). Efforts such as these help bridge the gap between healthcare providers and their patients.

\section{Sexual Minority Women and Healthcare in Lebanon}

In contrast to the U.S., the meager body of research pertaining to SMW in Lebanon does not shed light on the local community's health needs. Among the available articles addressing Lebanese LGBT individuals, very few seem to address the health needs of SMW. Consequently, one has to rely on international data and then extrapolate to Lebanon. However, from the little that exists in the local literature, it is suggested that sexual health is affected by sociocultural contexts, thus U.S. findings might not entirely mirror the local population. A study by Gereige et al. (2018) comparing the sexual health of SMW and heterosexual women living in Lebanon found that contrary to studies in the U.S., the rates of cervical cancer screening with a PAP smear among SMW and their heterosexual counterparts were similar (42\%). This number however, is drastically 
lower than the number of pap tests done on SMW and heterosexual women in the U.S. (White et al., 2017; Gereige et al., 2018). The study also showed that significantly more SMW had heard of PAP smears than heterosexual women. SMW asking their physician for a PAP smear directly might explain the similarity in numbers among the two groups of women (Gereige et al., 2018). SMW are more likely to be tested for sexually transmitted infections, and about half of the SMW in the study reported being comfortable in sharing their sexual orientation with their physician. ${ }^{19}$ These findings suggest that SMW are better health advocates for themselves than one would expect given the structural obstacles they face when seeking out medical help. An alarming finding was that $18 \%$ of SMW reported not having access to health care when they needed it as opposed to their heterosexual counterparts who never experienced this issue (Gereige et al., 2018). Despite the differences noted, the study did find some similarities between SMW in Lebanon and the U.S. SMW were found to have more sexual partners, earlier first sexual experiences (Matthews et al., 2004), and more unwanted sexual contact (Lehavot et al., 2012) than their heterosexual counterparts (Gereige et al., 2018). When it comes to physicians, a study by El-Kak et al. (2004) showed that only one-third of obstetricians and gynecologists in Lebanon take the time to specifically ask their patients about sexual health. In fact, one study (not published in a peerreviewed journal) showed that among Lebanese physicians in internal medicine, family medicine, and obstetrics and gynecology (OBGYN), only 50\% counsel their patients about sexual health practices, and only one-third of them ask about the patient's sexual preference (El-Kak, 2009). It also showed that $85.7 \%$ of obstetricians and gynecologists in Lebanon rely on "reading scientific publications" to improve their knowledge and skills in sexual health, and rarely rely on continuing medical education courses to update or improve (El-Kak, 2004).

Sociocultural and legal climate of SMW in Lebanon

This knowledge gap is exacerbated by prevailing sociocultural norms in Lebanon which can be particularly conservative in regard to sexuality. Fear of public opinion and a backlash regarding sexuality could be a factor influencing disclosure rates of sexual behavior among women to their providers. When it comes to SMW, it is important to note that they live in an environment where the majority consider homosexuality "immoral as well as sinful" and think that homosexuals should try to overcome their "feelings" (Kohut, 2013; Arab Foundation for Freedoms and Equality, 2015). 
A report by the United Nations Human Rights Counsel considers Article 534 from the Lebanese Penal Code-which criminalizes non-heterosexual sex, specifically sodomy-a major factor preventing the Lebanese LGBT population from having easy access to clinical services (Abdessamad \& Fattal, 2014). In 2009 however, a Batroun judge refused to apply Article 534 in regards to people engaging in same-sex relations citing it was not against the "rules of nature." In the following years, several judges followed suit and ruled in favor of people belonging to sexual minority groups (Girijashanker \& Leebron, 2018). On the legal front, these events are considered victories, albeit small, in favor of Lebanese sexual minority groups.

As for LGBT healthcare in Lebanon, the situation is far from ideal. In their paper, Abdessamad and Fattal explain how political turmoil, religious influences, unqualified healthcare professionals, outdated laws and lack of educational resources in Arabic, among others, all contribute to the lack of proper healthcare for the LGBT community in Lebanon (Abdessamad \& Fattal, 2014). Another contributing factor is the lack of a governing medical body that can draft official guidelines for healthcare providers with patients from the LGBT community, similar to those published by GLMA in the U.S. As a result, physicians are left without a reference to guide their approach to this community. Furthermore, the attitudes of Lebanese physicians regarding the LGBT community vary greatly, with approximately $50 \%$ stating that they would not tend to the needs of a homosexual patient (El-Kak, 2009). It is important to note that among those same physicians, 93.1\% reported never having received adequate training with regards to LGBT health. Fortunately, about $63.9 \%$ of respondents are willing to receive such education (El-Kak, 2009).

A report published by Outright Action International, an organization that aims to advance human rights for LGBTIQ people everywhere, examines the situation of sexual minority groups in Lebanon, Jordan, Tunisia and Morocco (Girijashanker \& Leebron, 2018). The report shows that despite individual differences, these countries share overarching similarities. All four countries have witnessed a wave of coalition-building and intersectional work among local LGBT organization which have increased visibility and security for sexual minority groups (Girijashanker \& Leebron, 2018). Despite more government resistance in Jordan and Morocco, informal networks which bring together professionals from different backgrounds, including healthcare, have managed to advance LGBT issues. The report also highlights that activists in Lebanon, Morocco, 
and Tunisia recognize that the LGBTIQ movement is mainly dominated by men. In response, sexual minority women activists are creating separate spaces for queer feminist organizing and building alliances with feminist organizations. In Tunisia for example, women's rights organizations started advocating for LGBT rights even before the 2011 revolution (Girijashanker \& Leebron, 2018)..

\section{Future Health Care Efforts in Lebanon}

The fact that some physicians are keen to learn how to modify their approach to healthcare in the LGBT community opens up a small window of opportunity for Lebanese non-governmental organizations (NGOs) working in the field of sexual health. Associations like Marsa, Helem, LebMASH, the Middle East \& North Africa Organization for Services, Advocacy, Integration \& Capacity-building (MOSAIC), and the Arab Foundation for Freedom and Equality (AFE) can help fill knowledge gaps in the field of healthcare in relation to non-normative sexualities and SMW. These NGOs launch awareness campaigns that target the general public like the "homosexuality is not a disease" campaign launched by LebMASH in 2016. Similarly, Marsa has undertaken many campaigns on topics ranging from HIV and transgender awareness, to menstrual periods and safer sexual practices. Beyond awareness campaigns, however, targeted interventions within the medical community at early stages, namely during undergraduate education, will ensure awareness among many future healthcare providers about LGBT health and ultimately prevent the stigma of working within that community. LebMASH has spearheaded raising awareness specifically among the healthcare community. One example is the LGBT health week running annually since 2017. It includes a conference targeting healthcare providers and a competencybuilding workshop targeting healthcare students (LebMASH, 2018). Student-led efforts from within the medical community are also underway. One example is the Lebanese Medical Students' International Committee's (LeMSIC) activities aimed at raising sexual health awareness in Lebanon. Another noteworthy initiative is LebGuide. LebGuide started as a research study of LGBTfriendly healthcare practitioners in 2017 lead by LebMASH and soon developed into a full-blown list of providers that is consistently updated with the newest information (Naal et al., 2019).

Although limited in number, there have been other endeavors led exclusively by the medical community that have also played a role in furthering sexual minority healthcare. In August of 2013, the Lebanese Psychological Association (LPA) and the Lebanese Psychiatric Society (LPS) 
issued a joint statement stating that homosexuality is not a disease and does not require treatment. In addition, the Lebanese Ministry of Public Health (2015) incorporated information centering around LGBT mental health as part of its national strategic plan. This move is important, as it indicates the beginning of a possible change in governmental policy climate that is conducive to advancing sexual minority health care in Lebanon. Balsam, a palliative care NGO, joined the LGBT health week in 2018 and 2019 and organized workshops that are the first of their kind in Lebanon and the Arab world. The workshops' goals were to meet the palliative and end of life needs of gender and sexual minorities. These are all examples of work that has already been done within our healthcare communities. If these efforts are multiplied, they could possibly change the face of LGBT healthcare in Lebanon.

Change may already be well underway. A study by Naal et al. (2019) shows more favorable attitudes of health care professionals, especially mental health professionals, toward LGBT patients when compared to older studies conducted in Lebanon. The study showed that $83 \%$ of participants did not think homosexuality is a mental disorder, and $93.6 \%$ of participants reported a willingness to take care of homosexual patients.

As for practicing physicians, a reevaluation of the way they communicate with their patients, including word choice and language modification, could go a long way in terms of building better physician-patient trust and openness. In addition to having to tread carefully while addressing these stigmatized issues with their patients, physicians in Lebanon have the added challenge of having to translate and adapt to Arabic the proper medical sexual terms they learn in English or French. In a country where public discourse centering around sexuality is often derogatory, creating an environment that is conducive to such topics can ease the whole patient encounter. Given that patients appear to be comfortable talking about their sexual health to their obstetricians and gynecologists (El-Kak et al., 2004; El-Kak, 2009), these physicians should take that opportunity and be prepared to explore that aspect of the woman's medical history. If SMW are offered a healthcare system conducive of trust they will feel more comfortable seeking medical and preventative care as well as having more honest conversations with their providers. Without establishing trust and rapport between a patient and physician, the patient's personal health and wellbeing are at stake. 


\section{Conclusion}

In conclusion, many large-scale obstacles in Lebanon stand in the way of giving SMW fair access to proper healthcare. These impediments, in turn, require large-scale interventions navigating barriers on the political, religious, educational, financial, and social front, to achieve the considerable progress needed in this field. It is, however, the healthcare provider's responsibility to play an active role in breaking down barriers faced by any minority group. We call on healthcare providers in Lebanon to use the few local educational activities offered by NGOs. We call on academics in Lebanon to add a question about sexual orientation with in demographic surveys in their studies to enrich the literature with needed local statistics. Change can also start in the confines of a physician's own clinic. By revising the approach to patient interviews and becoming more sensitive to patients' sexual practices, physicians have the potential to provide more holistic care to all patients across varying sexual identities. All these efforts on an individual basis we hope would culminate in improving the patient-doctor one-on-one interaction in the clinic, thereby building the trust and rapport that are a first step to ensuring better health status for SMW on a much larger scale. 


\section{References}

Abdessamad, H. M., \& Fattal, O. (2014). Lebanese Medical Association for Sexual Health: Advancing lesbian, gay, bisexual, and transgender health in Lebanon. LGBT Health, 1(2), 79-81.

https://doi.org/10.1089//gbt.2013.0039

American Cancer Society. (2005). Cancer facts for lesbians and bisexual women. https://www.cancer.org/healthy/find-cancer-early/womens-health/cancer-facts-for-lesbians-andbisexual-women.html

American College of Obstetricians and Gynecologists. (2005). Special issues in women's health.

Arab Foundation for Freedoms and Equality. (2015). As long as they stay away. http://afemena.org/wpcontent/uploads/2015/12/Report-high-resolution.pdf

Blosnich, J. R., Farmer, G. W., Lee, J. G., Silenzio, V. M., \& Bowen, D. J. (2014). Health inequalities among sexual minority adults: Evidence from ten US states, 2010. American Journal of Preventive Medicine, 46(4), 337349. https://doi.org/10.1016/j.amepre.2013.11.010

Davis, V., Christilaw, J. E., Edwards, C., Francoeur, D., Grant, L. J., \& Parish, B. (2000). Lesbian health guidelines. Journal SOGC, 22(3), 210A-213A. http://www.doi.org/10.1016/s0849-5831(16)31479-3

Dean, L., Meyer, I. H., Robinson, K., Sell, R. L., Sember, R., Silenzio, V. M., et al. (2000). Lesbian, gay, bisexual, and transgender health: Findings and concerns. Journal of the Gay and Lesbian Medical Association, 4(3), 102-151.

Diamant, A. L., Lever, J., \& Schuster, M. A. (2000). Lesbians' sexual activities and efforts to reduce risks for sexually transmitted diseases. Journal of the Gay and Lesbian Medical Association, 4, 41-48. https://doi.org/10.1023/A:1009513623365

El-Kak, F. (2009). Homophobia in clinical services in Lebanon: A physician survey. Unpublished Report. American University of Beirut.

El-Kak, F., Jurdi, R., Kaddour, A., \& Zurayk, H. (2004). Gender and sexual health in clinical practice in Lebanon. International Journal of Gynecology \& Obstetrics, 87(3), 260-266.

https://doi.org/10.1016\%2Fj.ijgo.2004.09.002

Gay and Lesbian Medical Association. (2006). Guidelines for care of lesbian, gay, bisexual, and transgender patients. http://rainbowwelcome.org/uploads/pdfs/GLMA guidelines 2006 FINAL.pdf

Gereige, J. D., Zhang, L., \& Boehmer, U. (2018). The Sexual Health of Women in Lebanon: Are There Differences by Sexual Orientation? LGBT Health, 5(1), 45-53. https://doi.org/10.1089//gbt.2017.0031

Girijashanker, S., \& Leebron, D. W. (2018). Activism and resilience: LGBTQ progress in the Middle East and North Africa. OutRight Action International. https://outrightinternational.org/sites/default/files/202210/ActivismResilience_Web.pdf

Graham, R., Berkowitz, B., Blum, R., Bockting, W., Bradford, J., de Vries, B., \& Makadon, H. (2011). The health of lesbian, gay, bisexual, and transgender people: Building a foundation for better understanding. Washington, DC: Institute of Medicine, 89-139. Retrieved 3 September 2018, from https://www.ncbi.nlm.nih.gov/pmc/articles/PMC1446710/

Human Rights Campaign Foundation. (2017). Healthcare Equality Index 2017. https://assets2.hrc.org/files/assets/resources/HEl-2017.pdf?_ga=2.148874162.468495970.1518802432366372500.1518802432

Institute of Medicine [IOM]. (2011). The health of lesbian, gay, bisexual, and transgender people: Building a foundation for better understanding. The National Academies Press. 
Kohut, A. (2013, June 04). The global divide on homosexuality. Pew Research.

https://www.pewresearch.org/global/2013/06/04/the-global-divide-on-homosexuality/

Lebanese Psychiatric Society. (2013, July). Statement from the Lebanese Psychiatric Society. Beirut: LPS Executive Committee

LebMASH. (2016, January 11). Shu el Sabab? [Video]. YouTube. https://www.youtube.com/watch?v=O_WKO34EoVE\&feature=you.tube

LebMASH. (2018, May 23). LGBT Health Week 2018. https://www.lebmash.org/lgbt-health-week-2018/

Lebanese Ministry of Public Health. (2015). Mental health and substance use: Prevention, promotion, and treatment.

https://www.moph.gov.Ib/userfiles/files/Mental\%20Health\%20and\%20Substance\%20Use\%20Strategy\%2 Ofor\%20Lebanon\%202015-2020-V1_1-English.pdf

Lebanese Psychiatric Society. (2013). Statement from the Lebanese Psychiatric Society (LPS). LebMASH. https://lebmash.org/2016/05/11/statement-from-the-lebanese-psychiatric-society-lps/

Lee, K. (2004). Working with lesbians. In Society for Sexual Health Advisers (SSHA) (Ed.) The Manual for Sexual Health Advisers (pp. 339-342). SSHA. http://www.ssha.info/wp-

content/uploads/ha_manual_2004_complete.pdf

Lehavot, K., Molina, Y., \& Simoni, J. M. (2012). Childhood trauma, adult sexual assault, and adult gender expression among lesbian and bisexual women. Sex Roles, 67(5-6), 272-284.

https://doi.org/10.1007\%2Fs11199-012-0171-1

Marrazzo, J. M., Koutsky, L. A., Eschenbach, D. A., Agnew, K., Stine, K., \& Hillier, S. L. (2002). Characterization of vaginal flora and bacterial vaginosis in women who have sex with women. The Journal of Infectious Diseases, 185(9), 1307-1313. https://doi.org/10.1086/339884

Marrazzo, J. M. (2000). Sexually transmitted infections in women who have sex with women: Who cares? Sexually Transmitted Infections, 76(5), 330-332. http://www.doi.org/10.1136/sti.76.5.330

Matthews, A. K., Brandenburg, D. L., Johnson, T. P., \& Hughes, T. L. (2004). Correlates of underutilization of gynecological cancer screening among lesbian and heterosexual women. Preventive Medicine, 38(1), 105113. https://doi.org/10.1016/j.ypmed.2003.09.034

Ministry of Public Health (MoPH). (2015, August). Mental health and substance use prevention, promotion, and treatment: Situation analysis and strategy for Lebanon 2015-2020. Beirut, Lebanon.

Naal, H., Abboud, S., Harfoush, O., \& Mahmoud, H. (2019). Examining the attitudes and behaviors of healthcare providers toward LGBT patients in Lebanon. Journal of Homosexuality, 67(13), 1902-1919. https://doi.org/10.1080/00918369.2019.1616431

Pan American Health Organization. (2014). CD52/18: Addressing the causes of disparities in health service access and utilization for lesbian, gay, bisexual and trans (LGBT) persons. https://iris.paho.org/handle/10665.2/4411

Ripley, V. (2011). Promoting sexual health in women who have sex with women. Nursing Standard, 25(51). 4146. http://www.doi.org/10.7748/ns2011.08.25.51.41.c8660

Substance Abuse and Mental Health Services Administration. (2012). Top health issues for LGBT populations information \& resource kit. https://store.samhsa.gov/system/files/sma12-4684.pdf

White, A., Thompson, T. D., White, M. C., Sabatino, S. A., Doria-Rose, P. V., Geiger, A. M., \& Richardson, L. C. (2017). Cancer screening test use-United States, 2015. Morbidity and Mortality Weekly Report, 66(8), 201-206. 